\author{
E. Laurikainen · J. M. Miller • A. L. Nuttall
}

W. S. Quirk

\title{
The vascular mechanism of action of betahistine in the inner ear of the guinea pig
}

Received: 25 June 1997 / Accepted: 20 August 1997

\begin{abstract}
The aim of this study was to investigate the mechanism and site of action of betahistine dihydrochloride in the inner ear of the guinea pig. Betahistine-evoked increases in cochlear blood flow (CBF) have been presumed to be due to the drug effect on the later wall capillary bed or larger feeding vessels in the cochlea vascular system. As such, the mechanism of action could be due to inhibition of $\mathrm{H}_{3}$ receptors. Betahistine may also have a direct effect on postsynaptic $\mathrm{H}_{1} / \mathrm{H}_{2}$ receptors and/or an effect modulated by other autonomic receptors. Betahistineevoked CBF responses were assessed by laser Doppler flowmetry in the presence of an $\mathrm{H}_{3}$ agonist ( ${ }^{\alpha} N$-methylhistamine dihydrochloride), an $\mathrm{H}_{3}$ antagonist (thioperamide), an $\mathrm{H}_{2}$ antagonist (cimetidine) or an $\alpha_{2}$ antagonist (idazoxan). The effects of betahistine on circulation in the anterior inferior cerebellar artery (AICA) and ipsilateral stria vascularis (SV) were assessed using intravital microscopy (IVM). Findings showed that betahistine increased CBF and reduced systemic blood pressure (BP). In contrast, ${ }^{\alpha} N$-methylhistamine dihydrochloride had no effect on baseline CBF or BP and did not influence betahistine-induced increases in $\mathrm{CBF}$. Thioperamide reversed the effects of betahistine on $\mathrm{CBF}$, but had no effect on baseline CBF or BP. Cimetidine had no marked effect on baseline $\mathrm{CBF}$ or betahistine-induced increases in $\mathrm{CBF}$ Idazoxan had no consistent effects on baseline $\mathrm{CBF}$, but abolished the effect of betahistine on CBF. The mean increase of red blood cell velocity in $\mathrm{SV}$ capillaries was
\end{abstract}

E. Laurikainen · J. M. Miller · A. L. Nuttall

Kresge Hearing Research Institute,

Department of Otolaryngology, The University of Michigan,

Ann Arbor, Michigan, USA

E. Laurikainen $(\bowtie)$

Department of Otorhinolaryngology,

Turku University Central Hospital, FIN-20520 Turku, Finland

W. S. Quirk

The Cochlear Microcirculation Laboratory,

Department of Otorhinolaryngology,

The Wayne State University, Detroit, Michigan, USA
$15 \%$ and occurred without a demonstrable change in capillary diameters. In contrast, the diameter of the AICA increased by $17-20 \%$, indicating that betahistine-evoked increases in CBF resulted primarily from vasodilatation of the AICA. We suggest that this effect may be mediated via presynaptic $\mathrm{H}_{3}$ heteroreceptors and autonomic $\alpha_{2}$ receptors.

Key words Cochlear blood flow · Cochlear physiology · Experimental vasodilatation - Betahistine treatment

\section{Introduction}

Betahistine dihydrochloride is considered to be one of the few vasoactive drugs that may have clinically beneficial effects on such inner ear disorders as Menière's disease and tinnitus [7]. Although vasodilatation due to direct stimulation of histaminergic $\mathrm{H}_{1}$ and $\mathrm{H}_{2}$ receptors has been suggested to be a contributing factor to these effects, betahistine is recognized to have only a weak effect on these receptors [8]. This study was carried out to further investigate the possible mechanism and site of action of betahistine on cochlear blood flow (CBF).

In a recent study, administration of betahistine either intravenously, or topically to the round window membrane, or via the anterior inferior cerebellar artery (AICA) resulted in a specific effect on cochlear vessels [4]. This response was not affected by promethazine as an $\mathrm{H}_{1}$ histaminergic antagonist. In separate studies Arrang et al. [1] have described a novel $\mathrm{H}_{3}$ inhibitory presynaptic receptor. Action at this presynaptic receptor may have two effects: stimulation may cause an inhibition of histamine release to the postsynaptic site, or it may interact with other autonomic receptors to co-modulate vessel tone. Elsewhere, Ischikawa and Sperilakis [3] have reported an interaction between $\mathrm{H}_{3}$ and adrenergic receptors in the peripheral nervous system.

As betahistine is recognized to be a strong $\mathrm{H}_{3}$ receptor antagonist [2], it is possible that betahistine-evoked increases in $\mathrm{CBF}$ could be due to inhibition of $\mathrm{H}_{3}$ receptors, 
thus causing an increase in histamine release and activation of postsynaptic $\mathrm{H}_{1}$ and $\mathrm{H}_{2}$ receptors. In addition, betahistine may have a weak, but direct, effect on postsynaptic $\mathrm{H}_{1}$ and $\mathrm{H}_{2}$ receptors and/or an effect modulated by other autonomic receptors. Indeed, in noradrenergic and cholinergic systems, the inhibitory presynaptic $\alpha_{2}$ receptor has been shown to mediate electrically stimulated increases in $\mathrm{CBF}$ [5]. However, it is possible that more than one of these mechanisms of action may contribute to the clinical benefits of betahistine.

In our current study, potential mechanisms of betahistine as cochlear blood flow were assessed by determining the effects of a specific $\mathrm{H}_{3}$ antagonist, an $\mathrm{H}_{3}$ agonist, an $\mathrm{H}_{2}$ antagonist and an $\alpha_{2}$ antagonist on betahistine-evoked increases in $\mathrm{CBF}$, using the guinea pig as an animal model. The site of action was also assessed by observing the vascular responses to betahistine in different regions of the cochlear vascular system, i.e., as the AICA and ipsilateral stria vascularis (SV).

\section{Materials and methods}

\section{Animals and preparation}

Eighteen healthy adult male and female pigmented guinea pigs (weighing 310-400 g) were used to assess the mechanism of action of betahistine. The study was consistent with the United States National Institute of Health (NIH) guidelines for the humane treatment of animals. The middle ear was examined in each animal prior to study in order to exclude ears with incidental infections. Animals were anesthetized with intraperitoneal pentobarbital (Nembutal) as $25 \mathrm{mg} / \mathrm{ml}$ or $0.6 \mathrm{ml} / \mathrm{kg}$ and in transmuscular fentanyl with properidol (Innovar) as $0.4 \mathrm{mg} / \mathrm{kg}$. Anestetics were provided by Sigma Chemicals (St. Louis, Mo., USA). An additional half dose of Innovar was administered every $30 \mathrm{~min}$ in order to maintain anesthesia.

Following tracheotomy, the carotid artery was cannulated for systemic blood pressure (BP) measurements while both external jugular veins were used for drug administration. The head was then fixed in a head restraint, and each animal being studied was wrapped in a heating pad with a feedback system in order to maintain core temperature at $38 \pm 1{ }^{\circ} \mathrm{C}$.

For laser Doppler flowmetry, TSI (TSI, Minnesota, USA) and Perimed PF3 (Perimed, Sweden) laser flowmeters were used as described in detail by Miller and Nuttall [6]. The tympanic bullae were exposed surgically using a ventral approach, the mucosa over the second turn of the cochlea was gently removed and petroleum jelly was applied between the laser probe and the bone in order to improve optical coupling. Measurements were made over the second turn by placing the probe perpendicular to the stria. CBF, BP and the conductivity of the cochlear vascular system $(R \mathrm{CBF} / \mathrm{BP})$ were recorded on a strip chart recorder. $R$ was used to express CBF independent of any changes in local perfusion pressure. Final re- sults were described in terms of the change $(\% \Delta \mathrm{CBF}$ and $\% \Delta \mathrm{BP})$ from mean baseline levels, with baseline levels determined over a period of at least $15 \mathrm{~min}$ before each experiment.

The effects of betahistine on circulation in the AICA and SV were also observed in two guinea pigs using intravital microscopy (IVM). Each animal's brainstem was exposed by removing the esophagus and deeper straight neck muscles, after which the bony skull base was drilled off. Following penetration of the aura, the AICA was characteristically found to branch from the basilar artery. For IVM observations of CBF, small windows were created with a 1-mm diamond drill in two or three sites over the membranous labyrinth. Systemically administered fluorescein was used to enhance the contrast of microcirculation in the lateral wall capillaries.

\section{Experimental procedures}

To verify a betahistine effect on CBF or study the interactions with other agents (see below), $12.4 \mathrm{mM}$ betahistine was administered systemically via a Sage 350 infusion pump into the left external jugular vein of six animals for $2 \mathrm{~min}$ at a rate of $0.3 \mathrm{ml} / \mathrm{min}$. All other drugs were infused into the right external jugular vein using a Sage model 354 infusion pump.

\section{Mode of action of betahistine}

${ }^{\alpha} N$-Methylhistamine dihydrochloride (RBI, Natick, Mass., USA) at a concentration of $12.5 \mathrm{mM}$ was infused at a rate of $0.31 \mathrm{ml} / \mathrm{min}$ for $2 \mathrm{~min}$ and was administered $10 \mathrm{~min}$ before any betahistine infusion in order to assess the effect of a specific $\mathrm{H}_{3}$ receptor agonist on $\mathrm{CBF}$ and the effect of chemical stimulation of $\mathrm{H}_{3}$ receptors on betahistine-evoked increases in $\mathrm{CBF}$ in four animals. This procedure was repeated twice in each animal following a 30-min recovery period between infusions.

The same procedures were used to assess the effects of $6,9,12$ and $16 \mathrm{mM}$ thioperamiede as a specific $\mathrm{H}_{3}$ receptor antagonist. Drug was obtained from RBI and was infused for 2 min at a rate of $0.3 \mathrm{ml} / \mathrm{min}$. Cimetidine (Sigma Chemicals) was used as a specific $\mathrm{H}_{2}$ antagonist and was infused in concentrations of 8, 16, 24 and $32 \mathrm{mM}$ at a rate of $0.3 \mathrm{ml} / \mathrm{min}$ for $2 \mathrm{~min}$ in five animals. Idazoxan (Sigma Chemicals) served as $\alpha_{2}$-antagonist at concentrations of 3 , 6,9 and $12 \mathrm{mM}$ and was infused at a rate of $0.3 \mathrm{ml} / \mathrm{min}$ for $2 \mathrm{~min}$ in five animals. Although a 30 -min recovery period was maintained between infusions, the result of each infusion represented a cumulative effect of the drug employed.

\section{Site of action of betahistine}

Observations of circulation in the AICA and SV during betahistine infusions were made using IVM via small windows over the basal, second and third turns of the cochlea. The effect of betahistine on AICA and SV diameter was also assessed under a surgical microscope at $\times 450($ AICA) or $\times 1000(\mathrm{SV})$ magnification (Fig. 3).
Table 1 Effects of ${ }^{\alpha} N$-methylhistamine dihydrochloride as $\mathrm{H}_{3}$ antagonist, thioperamide as $\mathrm{H}_{3}$ antagonist, cimetidine as $\mathrm{H}_{2}$ antagonist and idazoxan as $\alpha_{2}$ antagonist on baseline cochlear blood flow $(C B F)$ and betahistine-evoked increases in $\mathrm{CBF}$

\begin{tabular}{lllll}
\hline & Receptor & $\begin{array}{l}\text { Mode of } \\
\text { action }\end{array}$ & $\begin{array}{l}\text { Effect on } \\
\text { baseline }\end{array}$ & $\begin{array}{l}\text { Effect on } \\
\text { betahistine-evoked } \\
\text { increases in CBF }\end{array}$ \\
\hline $\begin{array}{l}\alpha N \text {-Methylhistamine } \\
\text { dihydrochloride }\end{array}$ & Histaminergic $\mathrm{H}_{3}$ & Agonist & None & None \\
$\begin{array}{l}\text { Cimetidine } \\
\begin{array}{l}\text { Idazoxan } \\
\text { Thioperamide }\end{array}\end{array}$ & $\begin{array}{l}\text { Histaminergic } \mathrm{H}_{2} \\
\alpha_{2}\end{array}$ & $\begin{array}{l}\text { Antagonist } \\
\text { Antagonist }\end{array}$ & $\begin{array}{l}\text { None } \\
\text { None }\end{array}$ & $\begin{array}{l}\text { None } \\
\text { Inhibtion } \\
\text { Inhibition }\end{array}$ \\
\hline
\end{tabular}


Fig. 1 The effect of betahistine infusion on cochlear blood flow $(C B F)$, blood pressure $(B P)$ and cochlear vascular conductivity $(C B F / B P)$.

Values shown are mean \pm $\operatorname{SEM}(n=5)$

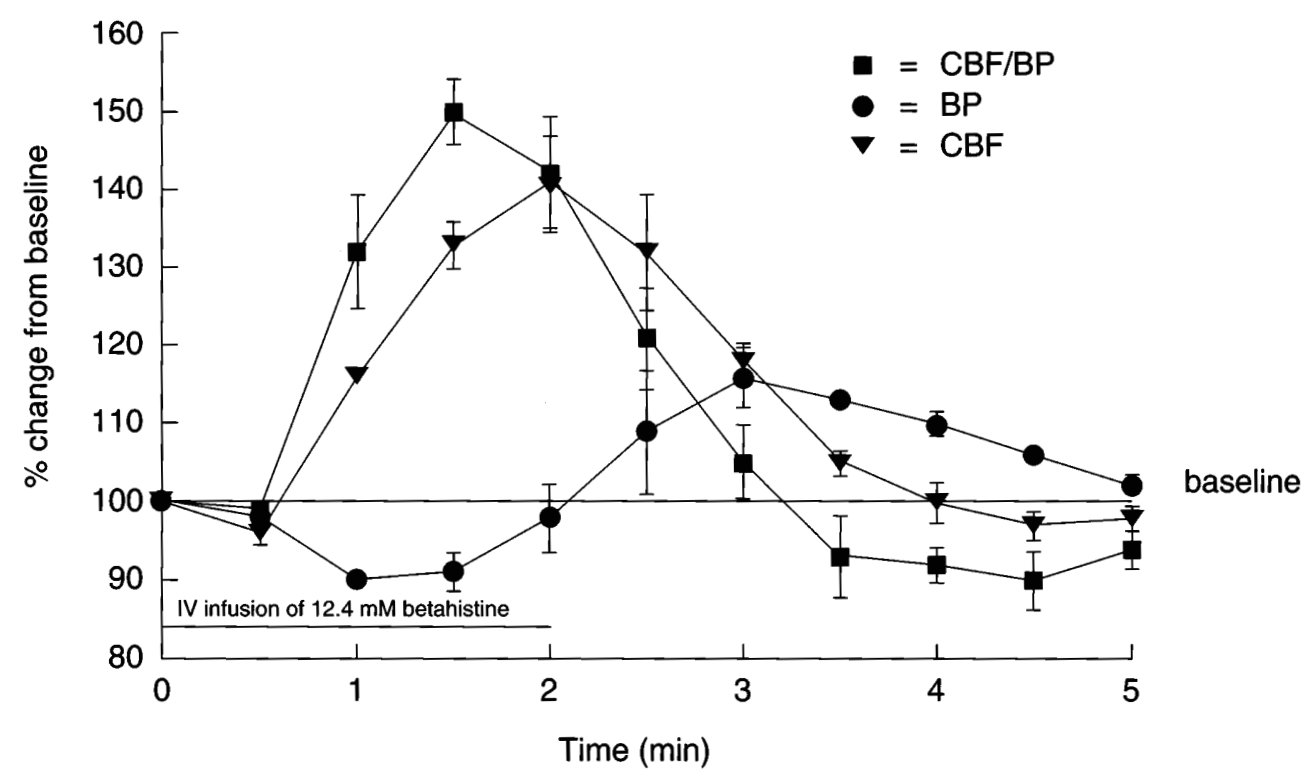

- Control

$\checkmark$ Idazoxan $12.5 \mathrm{mM}$

- Idazoxan $25 \mathrm{mM}$

- Idazoxan $50 \mathrm{mM}$ sented are from one representative experiment

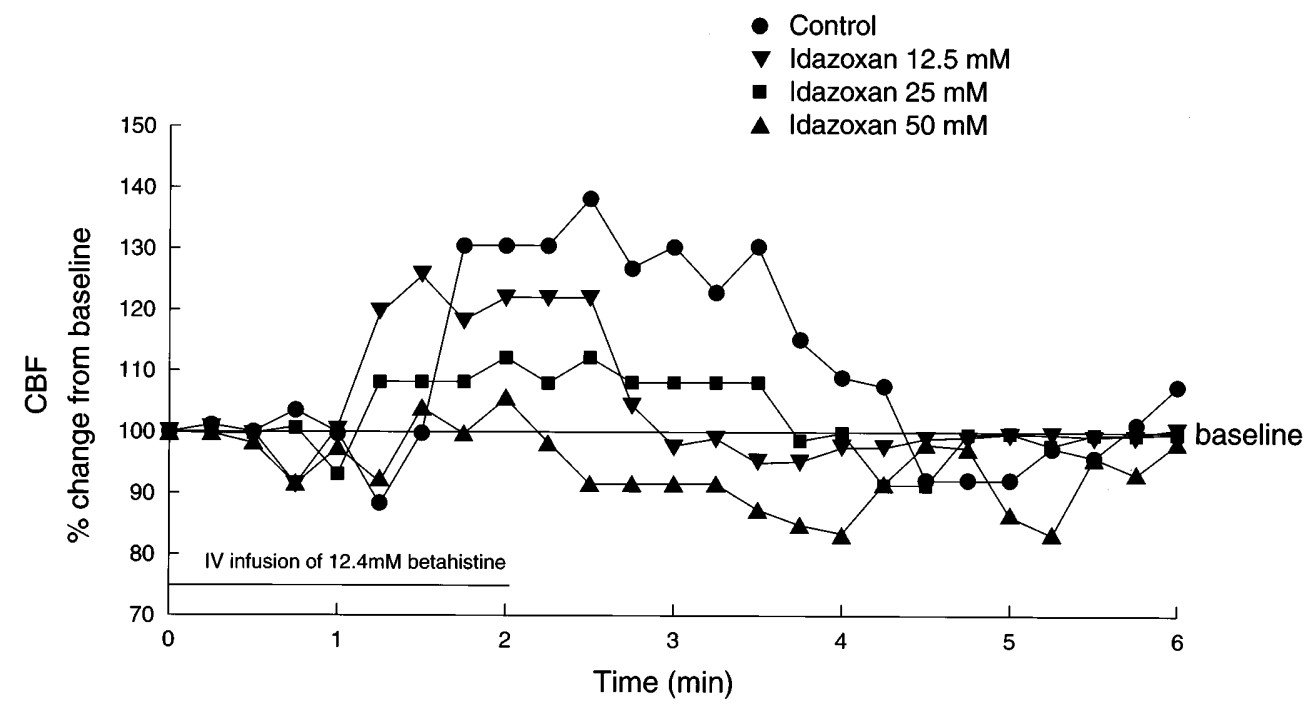

\section{Results}

Each infusion of betahistine resulted in a mean increase of $40 \%$ in CBF and a mean decrease of $10 \%$ in systemic BP compared with baseline (Fig. 1). Due to systemic effects, the conductivity of the vascular bed in the cochlea increased by up to $50 \%$ above baseline. CBF returned to baseline levels within 3-4 min of the infusion being terminated.

Mode of action of betahistine

As shown in Table 1, betahistine infusions resulted as an increased CBF. In contrast, ${ }^{\alpha} N$-methylhistamine dihydrochloride had no significant effect on baseline CBF or $\mathrm{BP}$ and did not influence betahistine-induced increases in CBF. However, thioperamide completely reversed the effects of betahistine on CBF. This latter effect showed lit- tle dose-dependence and was almost maximal at the lowest dose used $(6 \mathrm{mM})$. As seen with ${ }^{\alpha} N$-methylhistamine dihydrochloride, thioperamide had no effect on baseline $\mathrm{CBF}$ or BP. Increasing doses of both ${ }^{\alpha} N$-methylhistamine dihydrochloride and thioperamide caused convulsions, followed by sudden cardiac arrest and immediate death, but without any specific changes in CBF.

Cimetidine had no marked effect on $\mathrm{CBF}$, although high doses (up to $30 \mathrm{mM}$ ) resulted in a reduction in $\mathrm{BP}$ and a subsequent reduction in $\mathrm{CBF}$. Cimetidine had no significant effect on betahistine-induced increases in CBF.

Idazoxan reduced baseline $\mathrm{CBF}$ in some animals by $5-10 \%$, but this reduction was not consistent throughout the study, and therefore its significance remains unclear. Further assessment in relation to the tonic level of autonomic activity is required. However, idazoxan abolished the effect of betahistine on CBF; this response showed some dose-dependency (Fig. 2). 

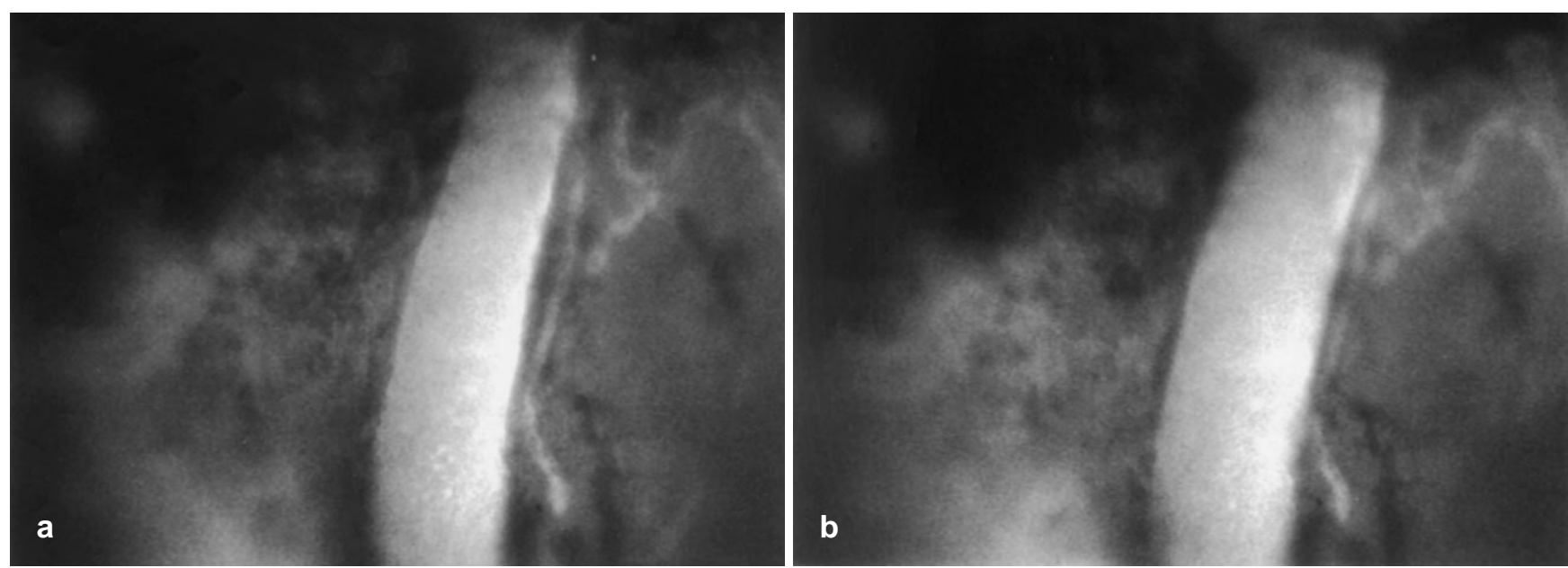

Fig. 3 a-c The effect of betahistine infusion on AICA diameter in one representative experiment. a Control infusion: vessel diameter $90 \mu \mathrm{m}$; b effect during drug infusion: vessel diameter $115 \mu \mathrm{m} ; \mathbf{c} 10$ min after drug infusion: vessel diameter $98 \mu \mathrm{m}$. Original magnification for AICA $\times 450$, for $\mathrm{SV} \times 1000$

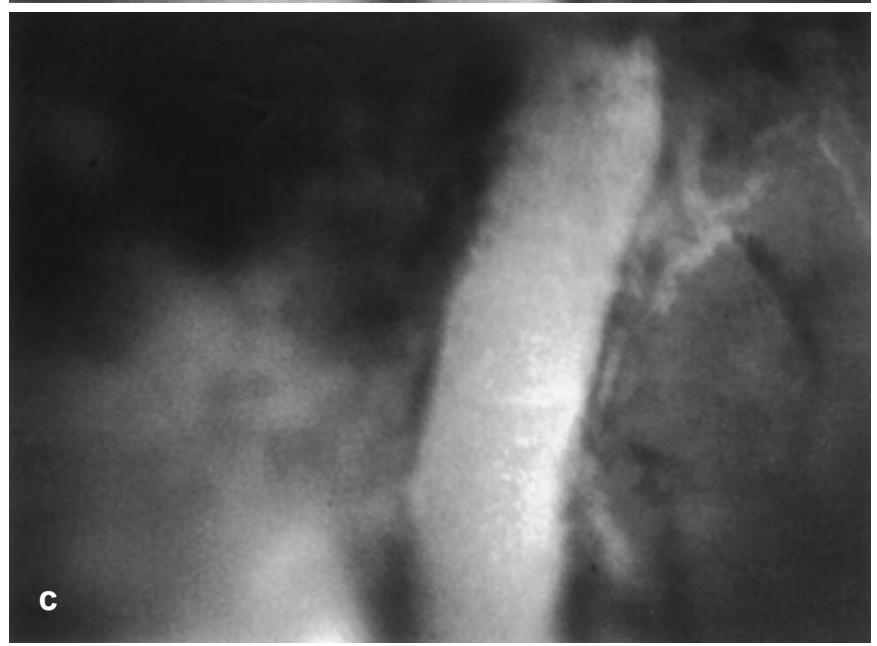

\section{Site of action of betahistine}

$\mathrm{CBF}$ during betahistine infusion was observed in a total of 30 vessels. The mean increase of red blood cell velocity in SV capillaries was $15 \%$ and occurred without a change in capillary diameter. The diameter of AICA increased by $17-20 \%$ (from $93-101 \mu \mathrm{m}$ to $105-121 \mu \mathrm{m}$ ).

\section{Discussion}

It has previously been shown that $\mathrm{H}_{1}$-receptor antagonists do not significantly affect betahistine-evoked changes in CBF [4]. The findings in our current study indicate that drugs acting at the $\mathrm{H}_{2}$ receptor also have no effect on the response to betahistine, while another $\mathrm{H}_{3}$ antagonist, thioperamide, inhibits the effects of betahistine. This suggests that betahistine-evoked increases in $\mathrm{CBF}$ are due to a specific effect on presynaptic $\mathrm{H}_{3}$ receptors in the cochlear vascular system. As the effect of betahistine is influenced by actions at presynaptic $\alpha_{2}$ receptors, the $\mathrm{H}_{3}$ receptors involved in the action of betahistine may be "heteroreceptors" that interact with both histaminergic and autonomic receptors in the periphery [3]. The finding that the specific $\mathrm{H}_{3}$ receptor antagonist, thioperamide, and the
$\mathrm{H}_{3}$ agonist, ${ }^{\alpha} N$-methylhistamine dihydrochloride, had no effect on baseline CBF indicates that these drugs can occupy $\mathrm{H}_{3}$ receptors (and so inhibit the action of betahistine), but they cannot interact with the vasoactive systems in the periphery necessary to affect CBF.

As it is difficult to measure modest changes in capillary diameter accurately using IVM and fluorescein, potential small changes associated with betahistine cannot be excluded. However, as betahistine receptors are thought most likely to be located on smooth muscle or on nerve innervating smooth muscle (neither of which are present in the lateral wall capillaries of the cochlea), such an effect is unlikely. The effects of betahistine on AICA and SV in our current study support these findings. This finding is also consistent with our earlier observations in which betahistine applied locally to the round window membrane produced a clear effect on cochlear electrophysiology but no change in CBF [4].

The cochlea has a strong autoregulatory capacity that compensates easily for small changes in cochlear circulation, such as those seen in AICA diameter in our current study. The marked increase in red blood cell velocity in the stria capillaries is therefore indicative of similar, more general smooth muscle responses in the inner ear vascular system (e.g., in the labyrinthine, spiral modiolar and radi- 
ating arterioles of the cochlea). Thus, betahistine is likely also to have an effect on the vestibular circulation.

The dose of betahistine used in our current study was selected to produce an effect that was clear, but well within a physiological range. The animals tolerated such treatment well and their respiratory and cardiovascular functions were only slightly affected by the infusion. The vascular actions of betahistine appear directly to affect not only the membranous vasculature in the cochlea, but also the larger afferent vessels derived from AICA. Thus, betahistine may affect the vestibular organ circulation as well as the cochlear circulation. This is an important observation in the search for the basic mechanism of action of betahistine in the treatment of vestibulo-cochlear disorders, although it must be realized that the dose infused in our current study was three to four times the usual oral dose employed in the clinical management of patients. This suggests that the effects of betahistine on CBF in patients are relatively small and may not be the only mechanism of action by which this drug exerts a beneficial effect on vestibulo-cochlear disorders.

\section{References}

1. Arrang JM, Garbarg M, Quach M, Jeremian E, Schwartz JC (1985) Action of betahistine and histamine receptors in the brain. Eur J Pharmacol 111:73-84

2. Arrang JM, Devaux B, Chodkiewiz JP, Schwartz JC (1988) $\mathrm{H}_{3}$ receptors control histamine release in human brain. J Neurochem $51: 105-108$

3. Ishikawa $\mathrm{S}$, Sperilakis N (1987) A novel class $\left(\mathrm{H}_{3}\right)$ of histamine receptors on perivascular nerve terminals. Nature 327:158-160

4. Laurikainen EA, Miller JM, Quirk WS, Kallinen J, Ren T, Nuttall AL, Gréman R, Virolainen E (1993) Betahistine induced vascular effects in the rat cochlea. Am J Otol 14:24-30

5.Laurikainen EA, Costa O, Miller JM, Nuttall AL, Ren TY, Masta R, Quirk WS, Robinson PJ (1994) Neuronal regulation of cochlear blood flow in the guinea pig. J Physiol Lond 480: $563-573$

6. Miller JM, Nuttall AL (1990) Cochlear blood flow. In: Shepard AP, Oberg PA (eds) Laser Doppler flowmetry. Kluwer, Norwell, Mass, pp 319-347

7. Schmidt J, Huizing EH (1992) The clinical drug trial in Menière's disease. Acta Otolaryngol (Stockh) [Suppl] 497:1189

8. Timmerman $\mathrm{H}$ (1990) Histamine $\mathrm{H}_{3}$ ligands: just a pharmacological tool or potential therapeutic agents? J Med Chem 33:411 